\title{
Orange is the New Asylum: Incarceration of Individuals with Disabilities
}

\author{
Becky Crowe $^{1}$ (D) $\cdot$ Christine Drew ${ }^{2}$ (D)
}

Accepted: 18 November 2020 / Published online: 22 February 2021

(C) Association for Behavior Analysis International 2021

\begin{abstract}
Individuals with disabilities and/or mental health concerns were historically removed from society and placed in institutions and asylums. Advocacy groups, drawing on civil rights movements, protested and lobbied for deinstitutionalization and increased inclusion of disabled individuals in schools and communities (Chapman et al., 2014). Although disabled individuals have more rights and access than ever before, they are still segregated in schools, encounter the judicial system more often, and are murdered by police (Reingle Gonzalez et al. in Journal of Disability Policy Studies 27:106-115, 2016). We examine the history and ongoing incarceration of individuals with differences in the United States by analyzing contextual variables, as well as systemic inequities, including the school-to-prison pipeline, access to services, and prison infrastructure. We offer resources and actionable ways for behavior analysts to begin antiracist and anti-disableist work, apply principles of behavior analysis to address personal and systemic racism, and engage in advocacy toward a more just and equitable future for all.
\end{abstract}

Keywords Behavior analysis $\cdot$ Disability $\cdot$ Incarceration $\cdot$ Mental health $\cdot$ Racism

In the United States, individuals with differences including intellectual and/or developmental disabilities and mental health conditions were isolated from their communities and families in institutions and asylums. Due to deinstitutionalization and civil rights movements, this is no longer socially acceptable, and we segregate individuals with differences in jails and prisons. Correctional facilities are the largest provider of mental health services in the country (Vallas, 2016).

Individuals deemed different, debilitated, disabled, or otherwise unable to contribute to the capitalist systems of production and labor were historically segregated and removed from society through placement in institutions and prisons (Chapman, Carey, \& Ben-Moshe, 2014). As the United States grapples with the inequities perpetuated against people of color through police brutality and homicide, calls for abolishing the police invite examination of the function and purpose of police. Law enforcement in the United States

Becky Crowe

rcrowe@uoregon.edu

1 Department of Special Education and Clinical Sciences, University of Oregon, 1589 E 15th St, Eugene, OR 97403, USA

2 Department of Special Education, Rehabilitation, and Counseling, University of Auburn, AL 36849 Auburn, USA arose out of a need to control and discipline individuals who did not conform to the idea of the ideal American citizen: a White, cisgender, heterosexual, cognitively and physically exceptional wealthy male. Data on the use of force by police depict an overrepresentation of Black, Indigenous, and people of color (BIPOC) as victims of police violence, within the judicial system, and housed in prisons (U.S. Commission on Civil Rights [USCCR], 2018).

In this article, we use identity-first language to refer to individuals with disabilities, which includes intellectual, developmental, and acquired disability conditions used in the reporting of data by the Centers for Disease Control and Prevention (CDC) and other agencies. We refer to individuals who are housed within the carceral systems as incarcerated individuals, which includes individuals in jails and public and private prisons. We refer to individuals with differences, which includes individuals with disabilities and individuals living with mental health conditions, to account for the combining of both identities under the label "individuals with disabilities" in federal and state reports. We do not intend to exclude, erase, or elide the differences between personfirst and identity-first language or cause harm to any individuals or communities; rather, we have sought to avoid making sweeping generalizations that omit the lived experiences of individuals. 
Disabled individuals were historically housed in institutions, asylums, and residential facilities prior to civil rights and grassroots advocacy movements that closed institutions and led to mandates for the inclusion of disabled individuals in schools and communities (Chapman et al., 2014). Despite appearances that disabled individuals have more rights, more access, and more legal protections than ever before in the United States, they are still segregated from their peers in schools, enter the criminal justice system more often than their peers, and are murdered by police more often (Reingle Gonzalez, Cannell, Jetelina, \& Froehlick-Grobe, 2016). Segregation of disabled individuals has shifted from disappearing them into state mental hospitals to imprisoning individuals with differences; some also consider housing disabled individuals in residential group homes and providing separate "sheltered work" to be forms of involuntary incarceration (Friedman \& Beckwith, 2014). When institutions closed following highly publicized narrative and visual accounts of abuse and neglect (Blatt \& Kaplan, 1966; Bly, 1887), those individuals were suddenly sent to family members, shifted into group homes, or ended up unhoused and underserved in their own communities (Vallas, 2016).

\section{The Intersectionality of Race and Disability}

Disability affects communities and groups of individuals differently based on race, wealth, and geography. BIPOC show the greatest prevalence of rates of disability, with White men least likely to experience living with a disabling condition (Centers for Disease Control [CDC], 2015). BIPOC have increased rates of asthma, mental illness, and disability due to environmental racism, which is zoning and segregation of communities that force BIPOC to live in communities with underfunded schools and other services due to racist taxation and near industrial sites and in older buildings with high levels of pollution (Rothstein, 2017). Due to inequities in economic privilege stemming from unequal access to education and employment, BIPOC with disabilities also experience disparities in accessing preventive health care services, qualifying for health insurance and accessible housing, and meeting their basic needs (Vallas, 2016). Epigenetic factors related to the heritability of developing posttraumatic stress disorder in response to trauma, as well as permanent genetic changes due to trauma, also predispose individuals of color to health and wellness disparities (Ryan, Chaudieu, Ancelin, \& Saffery, 2016). All of these factors contribute to the increased prevalence of disability among individuals who are not wealthy White men and increase the impact that impairments have on people's lives (CDC, 2015).

Examining mass incarceration requires an intersectional lens: Individuals with multiple sites of marginalized identity make up most of the prison population. Using interviews of both state and federal prisoners from a 2004 Bureau of Justice Statistics data set, researchers identified that individuals with a self-reported disability comprise $41 \%$ of prisoners in the United States, most often reporting experiencing learning disabilities. Individuals in prison were disproportionately Black (41\%), did not have a high school diploma (72\%), and had received public assistance as children (32\%; Reingle Gonzalez et al., 2016). According to the last U.S. census, Black-identifying individuals comprise only $13.4 \%$ of the U.S. population, $87.7 \%$ of all census-takers report having at least a high school diploma, and only $8.6 \%$ of respondents under 65 years report living with a disability (U.S. Census Bureau, 2019).

Economic factors contributing to the overrepresentation of disabled individuals in prisons relate directly to the capitalist foundations of the United States: Individuals seen as less productive and a drain on community resources are considered not worth rehabilitating and not worth educating, and thus are less qualified for employment or education (Chapman et al., 2014). Homelessness is a crime in most American cities, with individuals struggling with addiction and mental illness (Rembis, 2014), as well as disabilities, criminalized and entering the justice system due to their inability to pay for housing (Vallas, 2016). Homelessness is a frequent and reoccurring point of contact between individuals in crisis and law enforcement.

\section{The Court System}

The Americans With Disabilities Act (ADA) protects disabled individuals from unjustified segregation. In 1999, the U.S. Supreme Court ruled in Olmstead v. L.C. that two women who were voluntarily admitted to a state-run hospital for mental illness-related concerns could not be kept against their will when transitioning to a community-based care setting was recommended by medical professionals. The court's opinion stated that "confinement in an institution severely diminishes the everyday life activities of individuals, including family relations, social contacts, work options, economic independence, educational advancement, and cultural enrichment" (U.S. Department of Justice Civil Rights Division, n.d.). This ruling meant that community-based services must be provided when appropriate, unopposed by those persons, and can be reasonably provided given community resources. Despite this decision, disabled individuals and/or those with mental illness continue to be arrested and incarcerated. Individuals experiencing mental health crises are at increased risk of incarceration due to the judgment by law enforcement that their behavior requires their segregation from society. Jails and prisons are increasingly sites for storing individuals experiencing crisis due to the lack of mental health services 
and disparities in access to services by individuals without economic privilege.

Individuals with intellectual and developmental disabilities (IDD) are considered poor witnesses and deemed incapable of understanding court proceedings and consequences, and the veracity of their testimony is considered questionable. These legal judgments do not preclude individuals with IDD from criminal sanctions but usually reduce their sentencing (The Arc, 2014). Individuals with IDD are protected from statesanctioned execution by the judicial system if they are deemed incompetent by the court system. Individuals with less obvious or invisible disabilities, such as individuals who are $\mathrm{d} /$ Deaf, hard of hearing, or have mild intellectual disabilities, do not receive appropriate accommodations and are sometimes not recognized as having a disabling condition requiring supports. As a result, these individuals are still processed through the regular court system and are eligible for full sentences.

\section{The Prison System and Disability}

The prison system is the largest care provider for individuals with serious mental illness (McCauley \& Samples, 2017), illustrating the connection between lack of access to care and imprisonment. Disabled individuals are at increased risk of experiencing homelessness, poverty, incarceration and reincarceration, and lack of access to adequate health care and other care services (Hartman, 2020) As the number of incarcerated people with physical and mental disabilities increases and as those individuals age within the prison system, more Americans are acquiring disabilities in prison due to injury, neglect, and illness. These inmates are experiencing the lack of services, medical care, and accommodations that prisons were never meant to include (Blanck, 2017). Incarcerated people with disabilities are injured more often in prison, are disproportionately victims of within-prison violence, and experience more significant health complications than incarcerated people without disabilities (Blanck, 2017). The nature of prison infrastructure and the lack of health care have exacerbated the risks of the global pandemic caused by SARS-CoV-2: Individuals in prisons are at increased risk of death and physical disability (Park \& Meagher, 2020). The advent of SARS-CoV-2 has also increased the inequities and difficulties faced by disabled individuals in accessing services, ranging from closure and restricted hours of clinics and services to lack of care providers (Hartman, 2020); these individuals are overwhelmingly Black and Brown women (President's Commission for People with Intellectual Disabilities, 2017).

Without access to services, including reasonable accommodations for activities of daily living or access to vocational and educational services, disabled individuals in prison have higher recidivism rates and lower rates of successful reintegration into communities upon their release (Blanck, 2017). This lack of access not only negatively impacts individuals' quality of life and personal outcomes but also is a legal violation of the ADA. Accommodations must be requested by an inmate unless their need is visible and obvious to prison officials; however, many disabilities are invisible: Mental health diagnoses that may worsen intermittently such as bipolar disorder, schizophrenia, and depression; intellectual disabilities; traumatic brain injury; and learning disabilities are not immediately apparent but directly impact the individual's understanding of prison procedures, legal proceedings, and constitutional rights (Blanck, 2017). When an inmate's needs are made clear, prison staff are not trained on how to provide necessary accommodations, such as communicating with individuals with sensory impairment, safely transferring or assisting individuals with mobility needs, or providing modifications to individuals with cognitive differences.

The physical infrastructure of prison was not built to accommodate or provide access for disabled individuals, resulting in many inmates serving their time in solitary confinement, segregating them from the greater population and education and work-related opportunities. With the increasing privatization of prisons and the building of prisons by private companies, barriers to access due to financial constraints or the minimization of added costs also negatively impact the quality of life and access for disabled individuals (Vallas, 2016). Hiring ADA coordinators to inspect and ensure accessibility is not a priority for prison administrators who are cutting spending to maximize profits for investors. Access to medication, medical care, and support to request medical care (e.g., assistance to understand and complete paperwork) is denied to disabled individuals. Access to equipment such as wheelchairs, prosthetic limbs, and so forth is limited, and the lack of personal care workers further erodes the quality of life and access for individuals with physical differences.

Individuals who are $\mathrm{d} /$ Deaf or hard of hearing and in prison do not have access to American Sign Language interpreters or captioning necessary for them to communicate with correctional officers or access legal services, let alone engage in social interaction with others (Helping Educate to Advance the Rights of the Deaf, n.d.). In some states, court systems charge individuals who need interpretation, despite this being a violation of federal law (Vallas, 2016).

\section{What Can Behavior Analysts Do?}

In this article, we use the term "behavior analysts" to include and encompass Board Certified Behavior Analysts, Board Certified Assistant Behavior Analysts, Registered Behavior Technicians, and those in training for certification. The following sections discuss issues particular to the incarceration 
of disabled individuals and offer ways for behavior analysts to address and reduce risk factors for imprisonment of disabled individuals.

\section{The School-to-Prison Pipeline}

The presence of school resource officers (SROs) in America's public education settings has been a cause for concern but is especially worrisome for BIPOC students who are disproportionately identified for special education services and who are overrepresented in the statistics of police use of force against citizens. Having armed police officers in schools erodes community trust in the school system, increases the likelihood of officer-student encounters, and contributes directly to children of color being arrested, jailed, and sent to juvenile detention facilities. Because there is no centralized database of incidents of police use of force and reporting to federal agencies is voluntary, the scope of SROs' use of force in American schools is unknown, other than highly publicized incidents of excessive violence against children by armed police officers in schools (Vitale, 2017). Behavior analysts should advocate for the removal of SROs from schools through petitions to local school boards to discontinue contracts with law enforcement.

Special education - often warehousing students whom the education system has labeled as deficient, uneducable, and failures - perpetuates unequal social divisions along race, class, and gender lines and reproduces economic disparities, racism, and segregation of students. Students of color are disproportionately identified under the subjective eligibility categories of emotional disturbance and learning disabilities. Although special education is intended to be a continuum of services and supports, identification as a special education student increases separation from peers, suspension and expulsion from schools, and placement on a nondiploma academic track (Erevelles, 2000).

The National Council on Disability (NCD) recommends the development and implementation of individualized functional behavior assessments (FBA) to drive the creation and use of individualized and function-based behavior intervention plans (BIPs); both of these are areas in which behavior analysts must have skills, training, and experience. Current special education legislation does not require an FBA prior to writing or implementing a BIP, and copy-and-paste BIPs abound in schools where school personnel are not trained in how to conduct an FBA nor in how to develop, implement, or iteratively revise an individualized BIP. Developing and implementing effective BIPs may also reduce the use of seclusion and restraint in schools, which are disproportionately deployed against students with disabilities (NCD, 2015). Instead of school staff relying on SROs to administer punishment-based contingencies with students, behavior analysts in schools should implement proactive behavior strategies through individualized education programs and BIP planning. School system funding for SROs should be reallocated to hire behavior analysts to complete FBAs, develop and monitor BIPs, implement multitiered interventions and supports, and provide training to school staff.

In May 2020, a 15-year-old named Grace was incarcerated in Michigan for a parole violation for not completing online schoolwork. Grace, who is Black, was held in jail, and a judge ruled that she was a threat to the community for previously fighting with her mother and taking a schoolmate's phone. Grace, not only a victim of racist school and policing practices, was condemned to further incarceration for not submitting schoolwork during a global pandemic. Grace is another statistic of a person with a disability incarcerated - another BIPOC child piped directly from special education services to prison and held in a state facility where she was at increased risk of exposure to SARS-CoV-2, had less access to education, and was forcibly separated from her mother (Cohen, 2020).

Every child is entitled to a free and appropriate education: The interpretation of "appropriate" has undergone scrutiny and legal contestation since the Individuals With Disabilities Education Act was first authorized in 1994. Behavior analysts must incorporate contextual variables such as heritage language, culture, and learning history and work with consumers to develop effective interventions to keep children in schools, reduce inequities in access to education services, and improve outcomes for students in America. Current ethics guidelines on cultural competency, the social validity of interventions, and stakeholder buy-in should be at the forefront of program planning. A further call to action for the field of behavior analysis is to expand the scope of research and practice beyond disabled individuals: $68 \%$ of practicing Board Certified Behavior Analysts report their scope of practice to be with autistic individuals, and $8 \%$ report working with individuals with developmental disabilities (Behavior Analyst Certification Board [BACB], n.d.). Areas in which the expertise of behavior analysts is essential include addressing disparities in education, overrepresentation of individuals of color in special education, inequities in access to rigorous curriculum and poor outcomes for students who have individualized education programs, and working toward a more equitable education and system of educational supports.

\section{Addressing Racism}

Critically engaging with personal biases, prejudices, and racism is the first step for every individual in the United States. Claiming that one is "not racist" or "doesn't see race" omits the hegemonic ideology of White supremacy upon which the nation was founded, by which the nation gained economic power, and through which those in power remain in power (Erevelles, 2000). Generations of genocide of Indigenous peoples, the exploitation of Black people during chattel slavery 
and their subsequent ongoing oppression, and the many multiple ways that White supremacy is killing, oppressing, debilitating, and harming have left the United States with entrenched systems of racism, heteronormativity, patriarchy, and ableism that directly affect the lives of every one of its citizens. Everyone should begin with the self-presentation of accurate information about the nation's origins and history and hone discrimination skills to identify false information and private events. Contextualizing the past and ongoing repercussions of policies and laws and learning about the material consequences of these systems of oppression are merely the first steps in antiracist work. Behavior analysts must commit to the ongoing and iterative work of antiracist thoughts and behaviors, speaking up against oppressive systems and biased behavior by others and actively working toward equity and dismantling systems of oppression and marginalization.

Behavior analysts are called to intervene on socially significant behavior and improve the lives of the individuals we work with. We have an ethical obligation to the science of behavior analysis to maintain education and training in necessary areas to provide services to individuals whose demographical identities differ from our own (BACB, 2014). Because disability prevalence is highest among BIPOC and women (CDC, 2015), behavior analysts have an obligation to understand the intersecting systems of marginalization and oppression that directly impact the quality of life of consumers; indeed, such systems of oppression are a root cause of higher rates of disabling conditions among BIPOC. Expanding the scope of evidence and research that behavior analysts read and engage with is a crucial first step: Reading about critical race theory (Crenshaw, Gotanda, Peller, \& Thomas, 1995), understanding history through counternarratives and the lived experiences of those whose accounts are not celebrated in textbooks, and situating consumers' lives within culture, geography, and time will increase behavior analysts' understanding of contextual variables, enrich their understanding of stakeholders' and consumers' lives, and enhance the effectiveness of individualized interventions. Table 1 is a starting point for learning, and we challenge behavior analysts to engage in this work.

\section{The Prison System}

We advocate for abolishing the prison system in the United States; however, we also realize that this is a large and longterm outcome aimed at changing the deeply rooted capitalist foundations of the United States. Abolishing the prison system, reallocating funding to restorative and transformative justice programs, and increasing community mental health services and other community care systems are our ultimate macrolevel goals. We, as individuals, cannot abolish the prison system; however, we can engage in microlevel changes to directly improve the lives of those impacted by the system and decrease the likelihood that more individuals will contact the carceral system. In what follows, we present some individuallevel changes that behavior analysts can advocate for and directly engage in to improve our communities and individual outcomes.

For individuals who are already incarcerated, prison systems and administrators can increase publicizing provision of ADA services, ensuring that individuals are informed and asked to report their needs and known required accommodations upon entering the facility. For individuals who may have never been diagnosed or informed that their needs were covered by an ADA-qualified disability, increasing access to services to evaluate, identify, and provide appropriate accommodations for individuals entering the carceral system. After identification providing regular reevaluations, similar to educational programs covered by the Individuals With Disabilities Education Act, would ensure that as needs change across the life span, individuals have access to the services they need.

We recommend training prison staff, starting at the top, to ensure that every single person who comes into contact with any incarcerated individual understands the ADA and its legal protections and receives training specific to the needs of individuals housed within the facility. Training a handful of prison staff is not sufficient: Staff go on leave or take days off, staff and inmates move within the prison facility, and thus having a select few individuals who understand accommodations and who are trained in specific needs will not address the disparities of access and will not improve quality of life. Prisons are often set up based on a system of increasingly harsh punishmentbased procedures that often disproportionately impact affect Black incarcerated individuals and incarcerated individuals with mental illnesses (Olson, 2016).

As behavior analysts know, punishment-based procedures have side effects including increases in other topographies of challenging behavior and emotional responding and distress and do not teach a new skill. Increasing understanding that individuals' behavior may not be oppositional noncompliance but may be related to an impairment or mental illness may reduce the use of punitive consequences within prisons, which do not ameliorate or reduce the individual's behavior (Blanck, 2017). Behavior analysts with experience in organizational behavior management (OBM) can, with appropriate supervision and skills, provide training and ongoing iterative support to prison staff regarding understanding disability and impairment and increasing skills such as deescalation and multiple communication modes to decrease negative interactions between staff and prisoners.

Within the prison system, reforming punishment and isolation practices by implementing positive behavior interventions and supports (PBIS), similar to those implemented in public schools, could decrease punitive and abusive measures such as solitary confinement. Utilizing PBIS in jails and prisons could increase the ease of transitioning to school following release from juvenile detention facilities for children, increase positive interactions 
Table 1 Brief List of Resources for Antiracist and Prison Abolition Information

\begin{tabular}{|c|c|c|}
\hline Topic & Book title & Author \\
\hline \multicolumn{3}{|l|}{ Racism/antiracism } \\
\hline \multirow[t]{4}{*}{ Foundational texts } & Sister Outsider & Audre Lorde \\
\hline & The Autobiography of Malcolm $X$ & Malcolm X and Alex Haley \\
\hline & $\begin{array}{l}\text { In Search of Our Mothers' Gardens: } \\
\text { Womanist Prose }\end{array}$ & Alice Walker \\
\hline & A People's History of the United States & Howard Zinn \\
\hline \multirow[t]{10}{*}{ Contemporary texts } & How to Be an Antiracist & Ibram X. Kendi \\
\hline & Stamped From the Beginning & Ibram X. Kendi \\
\hline & The New Jim Crow & Michelle Alexander \\
\hline & We Charge Genocide & William L. Patterson (Ed.) \\
\hline & Sing, Unburied, Sing & Jesmyn Ward \\
\hline & White Fragility & Robin DiAngelo \\
\hline & Between the World and Me & Ta-Nehisi Coates \\
\hline & Just Mercy & Bryan Stevenson \\
\hline & So You Want to Talk About Race & Ijeoma Oluo \\
\hline & How We Get Free & Keeanga-Yamahtta Taylor (Ed.) \\
\hline \multicolumn{3}{|l|}{ Abolishing prison } \\
\hline & Disability Incarcerated & $\begin{array}{l}\text { Liat Ben-Moshe, Chris Chapman, } \\
\text { and Allison C. Carey }\end{array}$ \\
\hline & The End of Policing & Alex Vitale \\
\hline & Are Prisons Obsolete? & Angela Davis \\
\hline & Blood in the Water & Heather Ann Thompson \\
\hline & $\begin{array}{l}\text { From the War on Poverty to the War } \\
\text { on Crime }\end{array}$ & Elizabeth Hinton \\
\hline & Locking Up Our Own & James Forman Jr. \\
\hline
\end{tabular}

between staff and inmates, and reduce rates of problem behavior within carceral facilities (Fernandez \& McClain, 2014). Ensuring that the use of PBIS is both culturally and contextually relevant is a challenge and a call to action that behavior analysts can work toward supporting and facilitating.

In addition to bringing experience with OBM and PBIS to the carceral system, behavior analysts can support prison and jail staff in providing trauma-informed care. Linking with mental health professionals and licensed social workers who have skills and training in trauma-informed care, particularly with individuals in the carceral system, will increase the skills and knowledge of behavior analysts and prison staff to better provide necessary services to promote healing, increase medical treatment compliance, and reduce the shame and fear of medical professionals (Tello, 2019).

At the federal level, increasing oversight and accountability of prison and jail adherence to ADA legislation is necessary to ensure that individuals within the judicial and carceral systems have access to the services and supports they need. Without supports, disabled individuals are at increased risk of incarceration, may not be able to advocate for their needs, will experience worsening health, are at increased risk of being victims of crimes within prison, and are denied access to educational and vocational services (Blanck, 2017).
Once in contact with the judicial system, individuals who require accommodations and modifications are not provided access: Only two states, Oregon and Washington, provide legal counsel to litigants with disabilities as an accommodation, several states do not permit service animals within courthouses, and courts in some states can charge individuals who need American Sign Language interpreters for the service (Vallas, 2016). Individuals are denied access to accommodations throughout the criminal and judicial system, resulting in higher rates of arrest, detainment, and incarceration. Advocating for equity, voting for public servants who actively protect and increase the rights of individuals once they contact the judicial system, supporting civil liberties and rights organizations, writing letters to legislative representatives, and educating more members of communities about the inequities and injustices embedded within the criminal justice system are all steps that behavior analysts, as members of local communities and informed consumers of public services, can become actively involved in.

\section{Reducing Recidivism}

Disabled individuals without criminal records already face discrimination and barriers to adequate housing, employment, 
Table 2 Actions at the Individual, Local, and Federal Levels That Behavior Analysts Can Support and Advocate For

\begin{tabular}{|c|c|c|}
\hline Action level & Actions & Organizations and resources \\
\hline \multirow[t]{10}{*}{ Individual } & Advocate for equity & https://www.showingupforracialjustice.org/ \\
\hline & Vote for public officials & https://www.usa.gov/local-governments \\
\hline & Support civil liberties and rights organizations & www.aclu.org \\
\hline & Communicate with representatives & https://www.house.gov/representatives/find-your-representative \\
\hline & Reducing education disparities & https://centerracialjustice.org/ \\
\hline & Starting a social justice-themed book club & $\begin{array}{l}\text { https://www.tolerance. } \\
\text { org/sites/default/files/2019-01/TT-Reading-For-Social-Justice-Guide.pdf }\end{array}$ \\
\hline & Engaging in changes to public policy/law & $\begin{array}{l}\text { https://eji.org/get-involved/ } \\
\text { https://www.joincampaignzero.org/ }\end{array}$ \\
\hline & Reducing disparities in research & https://researchcenters.ku.edu/center-study-injustice \\
\hline & Support community-based services & https://www.mutualaidhub.org/ \\
\hline & Supporting and engaging with disability rights groups & $\begin{array}{l}\text { https://adapt.org/ } \\
\text { https://dralegal.org/ }\end{array}$ \\
\hline \multirow[t]{10}{*}{ Local } & Abolish jails & \\
\hline & End criminalization of homelessness & https://nlchp.org/housing-not-handcuffs/ \\
\hline & End criminalization of addiction & $\begin{array}{l}\text { https://www.hrw. } \\
\text { org/news/2016/10/12/us-disastrous-toll-criminalizing-drug-use }\end{array}$ \\
\hline & Increase supported housing & https://acl.gov/programs \\
\hline & Increase access to services & https://www.ncbi.nlm.nih.gov/pmc/articles/PMC5775117/ \\
\hline & Increase transportation infrastructure & https://www.transportation.gov/mission/health/equity \\
\hline & Provide accommodations within justice system & https://dredf.org/ \\
\hline & Provide accommodations within carceral system & https://adata.org/factsheet/corrections \\
\hline & Train judicial staff on ADA compliance & https://www.ada.gov/accessiblecells.htm \\
\hline & Abolish SROs & $\begin{array}{l}\text { https://www.washingtonpost. } \\
\text { com/education/2020/06/12/schools-police-george-floyd-protests/ }\end{array}$ \\
\hline \multirow[t]{9}{*}{ State/federal } & Abolish carceral system & $\begin{array}{l}\mathrm{http}: / / \text { project-nia.org/ } \\
\mathrm{https://www.themarshallproject.org/records/4766-prison-abolition} \\
\mathrm{http} / / \text { criticalresistance.org/chapters/ }\end{array}$ \\
\hline & $\begin{array}{l}\text { Fund training for social workers, teachers, therapists, and } \\
\text { counselors }\end{array}$ & $\begin{array}{l}\text { https://grantsplus.com/racial-justice-grants/ } \\
\text { https://www.racialhealthequity.org/funding }\end{array}$ \\
\hline & Fund public housing & https://nlihc.org/explore-issues/publications-research/advocates-guide \\
\hline & Fund transportation infrastructure & \\
\hline & Increase supported housing & https://www.aapd.com/advocacy/housing/ \\
\hline & Advocate for prisoners with disabilities & http://www.avidprisonproject.org/ \\
\hline & Train judicial and prison staff on ADA compliance & \\
\hline & Reform punishment-based contingencies & https://www.pbis.org/topics/juvenile-justice \\
\hline & Increase data collection on prison: disabled individuals & http://www.avidprisonproject.org/ \\
\hline
\end{tabular}

Note. ADA Americans with Disabilities Act, $S R O$ school resource officers.

and access to medical care and other support services; this is further compounded by the legal discrimination against individuals with criminal records by employers and housing authorities (Vallas, 2016). Many recently released individuals do not have secure or accessible housing available upon release and either stay in homeless shelters or are unhoused, resulting in these individuals repeatedly having contact with police and reentering the criminal justice system. Individuals who are released are not provided with resources to access employment, medical or behavioral health services, medication, or other needed supports and services, further exacerbating the inequities to access that are faced by disabled individuals (Vallas, 2016) and increasing their risk of experiencing a medical or mental health crisis and reentering the carceral system.

One pathway to prison is repeated run-ins with the criminal justice system, including for activities related to being unhoused. There are now more people with mental health conditions and disabilities in prisons than in state hospitals (Vallas, 2016). Community-based services for disabled individuals or those with serious mental illness are far cheaper 
than housing individuals in prisons and jails, even when intensive services and supportive housing are provided (Vallas, 2016). Housing First, a program implemented in Salt Lake City, Utah, provided highly subsidized housing to individuals living with a disability and without shelter with the justification that providing housing was cheaper than providing emergency services through hospital emergency rooms and jails (McEvers, 2015). Funding programs such as Housing First - and ensuring that funding allocation keeps pace with rising inflation and stagnant wages and accounts for increases in need due to national events such as the opioid epidemic or job loss due to a global pandemic — should be a priority for all municipalities. Behavior analysts can advocate for ballots and bills to establish programs in their local area, vote for and support legislators who back those bills, and share information about the effectiveness of such programs with local government officials.

In addition to advocating for and supporting increased community-based services, behavior analysts can work with recently released individuals and ensure their successful transition from prison to their community. Programs aimed at supporting and assisting recently released individuals transition back to community living by providing supported housing, teaching and assisting with navigating local and state systems, and linking individuals with medical care, employment, and housing opportunities are all programs that behavior analysts can facilitate or set up. Reducing the number of people whose entry into carceral systems is because of housing needs involves advocating and voting against policies that criminalize homelessness, increasing access to safe shelter for individuals with uncertain or inconsistent housing, and voting for policies to increase access to safe shelter for disabled individuals.

Last, behavior analysts can bring expertise and skills in data collection to evaluate processes at all levels of the judicial and carceral systems, especially with regard to compliance with the ADA. Data on rates of incarceration of disabled individuals also need to include students with disabilities in correctional facilities: To address problems of overrepresentation and inequities in access to educational services, we must first understand how many children with disabilities are impacted and in what ways. Behavior analysts can provide support in the areas of collecting and analyzing data to evaluate and develop interventions to increase access and equity and determine areas of need. Further areas that behavior analyst expertise is needed are determining the prevalence of disabilities acquired by citizens within the carceral system; and systematizing data on officer-citizen incidents, prison staff-inmate incidents, and resultant injury or disability are all areas of great need. The use of data-driven decision making is an area of strength and expertise within behavior analysis: These skills are crucial and requisite to begin changing the treatment of disabled individuals and/or mental health needs in the criminal justice system in America.

We close with a list of resources in Table 2 of actions at the individual, local community, and federal levels for behavior analysts. Some of the resources are community-based organizations with local chapters; others are national organizations working at both the local and federal levels to effect reform and abolish inequitable systems. These links are a jumping-off point for gaining information, connecting to organizations, and beginning antiracist and prison abolition work. We invite behavior analysts, related professionals, and their acquaintances to engage with these resources, seek out local organizers, and use their ballots, as well as continue direct service provision toward a more just, equitable, and better future.

Funding This research was partially supported by a U.S. Department of Special Education Office for Special Education Programs Leadership Grant H325D150082, with co-primary investigators Laura Lee McIntyre, Kent McIntosh, and Wendy Machalicek, University of Oregon.

\section{Declarations}

Conflict of interest We have no conflicts of interest to disclose.

\section{References}

The Arc. (2014). Joint position statement with the American Association on Intellectual and Developmental Disabilities: Criminal justice system. http://thearc.org/wp-content/uploads/2019/08/16-117-TheArcs-Position-Statements_B4_Criminal-Justice-System-1.pdf

Behavior Analyst Certification Board. (n.d.). BACB certificant data. https:/www.bacb.com/bacb-certificant-data/

Behavior Analyst Certification Board. (2014). Professional and ethical compliance code for behavior analysts. https://www.bacb.com/wpcontent/uploads/2020/05/BACB-Compliance-Code-english 190318.pdf

Blanck, P. (2017). Disability in prison. Southern California Interdisciplinary Law Journal, 26(2), 309-332.

Blatt, B., \& Kaplan, F. (1966). Christmas in purgatory. Allen \& Bacon. Bly, N. (1887). Ten days in a mad-house. Munro: Ian L.

Courtney-Long, E.A., Carroll, D.D., Zhang, Q.C., Stevens, A.C., GriffinBlake, S., Armour, B.S., \& Campbell, V.A. (2015). Prevalence of disability and disability type among adults-United States, 2013. Morbidity and Mortality Weekly Report, 64(29), 777-808. https:// doi.org/10.15585/mmwr.mm6429a2

Chapman, C., Carey, A. C., \& Ben-Moshe, L. (2014). Reconsidering confinement: Interlocking locations and logics of incarceration. In L. Ben-Moshe, C. Chapman, \& A. C. Carey (Eds.), Disability incarcerated (pp. 3-24). Palgrave Macmillan.

Cohen, J. S. (2020). A teenager didn't do her online schoolwork. So a judge sent her to juvenile detention: ProPublica Illinois https://www. propublica.org/article/a-teenager-didnt-do-her-online-schoolworkso-a-judge-sent-her-to-juvenile-detention.

Crenshaw, K., Gotanda, N., Peller, G., \& Thomas, K. (1995). Critical race theory: The key writings that formed the movement. The New Press. 
Erevelles, N. (2000). Educating unruly bodies: Critical pedagogy, disability studies, and the politics of schooling. Educational Theory, 50(1), 25-47.

Fernandez, M., \& McClain, D. (2014). Georgia's juvenile justice system applies new framework to modify youth behavior trends. Corrections Today, 76, 18-19.

Friedman, M., \& Beckwith, R.-M. (2014). Self-advocacy: The emancipation movement led by people with intellectual and developmental disabilities. In L. Ben-Moshe, C. Chapman, \& A. C. Carey (Eds.), Disability incarcerated (pp. 237-254). Palgrave Macmillan.

Hartman, M. (2020). An unequal response: COVID-19 and disability. Johns Hopkins School of Public Health Expert Insights https:// www.jhsph.edu/covid-19/articles/an-unequal-response-covid-19and-disability.html.

Helping Educate to Advance the Rights of the Deaf. (n.d.). \#DeafInPrison campaign fact sheet. https://behearddc.org/wpcontent/uploads/2018/11/DeafInPrison-Fact-Sheet-.pdf

McCauley, E., \& Samples, L. (2017). Navigating the disability determination process from the perspective of incarcerated adults with serious mental illness. Community Mental Health Journal, 53, 905915.

McEvers, K. (2015). Utah reduced chronic homelessness by $91 \%$; here's how. All Things Considered. https://www.npr.org/2015/12/10/ 459100751/utah-reduced-chronic-homelessness-by-91-percentheres-how

National Council on Disability. (2015). Breaking the school-to-prison pipeline for students with disabilities. https://ncd.gov/publications/ 2015/06182015

Olson, J. C. (2016). Race and punishment in American prisons. Journal of Public Administration Research and Theory, 26(4), 758-768.

Park, K., \& Meagher, T. (2020). A state-by-state look at the coronavirus in prisons. The Marshall Project. https://www.themarshallproject. org/2020/05/01/a-state-by-state-look-at-coronavirus-in-prisons

President's Commission for People With Intellectual Disabilities. (2017). Report to the president 2017: America's direct support workforce crisis. https://www.nadsp.org/wp-content/uploads/2018/02/PCPID2017 -Americas-Direct-Support-Workforce-Crisis-low-res.pdf
Reingle Gonzalez, J. M., Cannell, B., Jetelina, K. K., \& Froehlick-Grobe, K. (2016). Disproportionate prevalence rate of prisoners with disabilities: Evidence from a nationally representative sample. Journal of Disability Policy Studies, 27(2), 106-115. https://doi.org/10. 1177/1044207315616809.

Rembis, M. (2014). The new asylums: Madness and mass incarceration in the neoliberal era. In L. Ben-Moshe, C. Chapman, \& A. C. Carey (Eds.), Disability incarcerated (pp. 139-159). Palgrave Macmillan.

Rothstein, R. (2017). The color of law: A forgotten history of how our government segregated America. Liveright Publishing.

Ryan, J., Chaudieu, I., Ancelin, M.-L., \& Saffery, R. (2016). Biological underpinnings of trauma and post-traumatic stress disorder: Focusing on genetics and epigenetics. Epigenomics, 8(11), 15531569. https://doi.org/10.2217/epi-2016-0083.

Tello, M. (2019). Trauma-informed care: What it is, and why it's important. Harvard Health Blog. https://www.health.harvard.edu/ blog/trauma-informed-care-what-it-is-and-why-its-important2018101613562

U.S. Census Bureau. (2019). QuickFacts table. https://www.census.gov/ quickfacts/fact/table/UsS/PST045219

U.S. Commission on Civil Rights. (2018). Police use of force: An examination of modern policing practices [Briefing report]. https://www. usccr.gov/pubs/2018/11-15-Police-Force.pdf

United States Department of Justice Civil Rights Division. (n.d.). Olmstead: Community integration for everyone. Information and Technical Assistance on the Americans with Disabilities Act. https://www.ada.gov/olmstead/olmstead_about.htm

Vallas, J. (2016). Disabled behind bars: The mass incarceration of people with disabilities in America's jails and prisons. Center for American Progress. https://www.americanprogress.org/issues/ criminal-justice/reports/2016/07/18/141447/disabled-behind-bars/

Vitale, A. (2017). The End of Policing. Verso.

Publisher's Note Springer Nature remains neutral with regard to jurisdictional claims in published maps and institutional affiliations. 